\title{
Differences in the behavior characteristics between Daphnia magna and Japanese madaka in an on-line biomonitoring system
}

\author{
Zongming Ren ${ }^{1,2}$, Zijian Wang $^{2, *}$ \\ 1. Yantai Institute of Coastal Zone Research, Chinese Academy of Sciences, Yantai 264003, China. E-mail: zmren@yic.ac.cn \\ 2. State Key Laboratory of Environmental Aquatic Chemistry, Research Center for Eco-Environmental Sciences, \\ Chinese Academy of Sciences, Beijing 100085, China
}

Received 09 July 2009; revised 18 August 2009; accepted 31 August 2009

\begin{abstract}
It is important to select suitable organisms to adapt the requirement of different environment monitoring purposes. Following our previous study, the behavioral responses of Daphnia magna and Japanese madaka (Oryzias latipes) were investigated and compared under flow-through conditions in an on-line biomonitoring system. The results showed that both $D$. magna and Japanese madaka had similar biological clock, but the circadian rhythms of Japanese madaka was more clearly recorded than that of $D$. magna. And the sensitivity of D. magna was about two orders of magnitudes higher than that of Japanese madaka in different types of toxic chemicals (dichlorovos, deltamethrin and cadmium chloride). However, when both animals were used in an on-line biomonitoring system, the life span of $D$. magna was less than 7 days and Japanese madaka could last for more than one month without feeding. Therefore, $D$. magna was proposed to be a more sensitive bioindicator and was suitable for short term monitoring the pollution events at concentration level closing to the water quality standard, while Japanese madaka was more suitable for the long-term monitoring for accidental discharges.
\end{abstract}

Key words: Daphnia magna; Japanese madaka; on-line biomonitoring; behavioral responses

DOI: $10.1016 / \mathrm{S} 1001-0742(09) 60166-2$

\section{Introduction}

Accidental chemical pollution, which may destroy the ecological balance of water environment and cause great damage to people's lives and property, has often occurred. In some circumstances, identification of water pollutants and polluters was not possible (Chai et al., 2004; Yang et al., 2008). Considerable progress has been made in recent years to develop an on-line biomonitoring capability as an acceptable alternative approach. At present, commercially available equipments including On-line Fluorescence Monitoring System (Rodriguez et al., 2002), Ultra-sensitive Daphnia-Toximeter (Green et al., 2003), the Multispecies Freshwater Biomonitor (MFB) (Gerhardt et al., 2002), and Biological Early Warning System (BEWs) (Li et al., 2007) have been applied in early warning of accidental pollution all over the world. Except on-line fluorescence monitoring system, which depends on the fluorescence of luminescent bacteria, the rest biomonitoring systems are all based on the behavioral responses of aquatic organisms, e.g., water fleas and fish.

Motility is a characteristic feature of many organisms that cannot be neglected as an important physiological factor in survival (Putman and Wratten, 1984; Ren et al., 2009a). Behavioral responses in organisms associated with stress and toxicant exposure provide novel information including short term and median lethal exposure effects, and the potential for mortality (Andrew et al., 2004; Ren et al., 2007), which cannot be gained from traditional toxicological methods. Therefore, in the biological early warning of accidental water environment pollution, the on-line monitoring of the behavioral responses of aquatic organisms is viable (Ren et al., 2007, 2009a, 2009b).

D. magna and Japanese madaka (Oryzias latipes) were often used as the representative of water fleas and fish in the on-line biomonitoring systems, e.g., DaphniaToximeter, MFB, and BEWs. The freshwater cladoceran D. magna Straus are normally considered as sensitive to contaminants (Sturm and Hansen, 1999; Rosa et al., 2006; Ren et al., 2007). This species has often been used in bioassays and environmental monitoring of aquatic systems due to the ease and economy of maintaining cultures (Tomasik and Warren, 1996; Martínez-Jerónimo et al., 2005; Heckmann et al., 2007). The Japanese Madaka is an extensively studied species and has been proposed as the standard test fish in the OECD guidelines (OECD, 1999). Many data related to behavior in madaka have been reported (Gray et al., 1999; Oshima et al., 2003; Gormley and Teather, 2003; Chon et al., 2005; Ren et al., 2007, 2009a, 2009b).

Since the beginning of 1980 s, the behavioral responses

\footnotetext{
* Corresponding author. E-mail: wangzj@ rcees.ac.cn
} 
of aquatic organisms had been applied in the on-line biomonitoring of aquatic systems. The results of DaphniaToximeter using D. magna suggested that the alarm rate of Daphnia-Toximeter could reach $100 \%$ in $2.5 \mathrm{mg} / \mathrm{L}$ $\mathrm{Cd}^{2+}$, and $50 \%$ in $0.5 \mathrm{mg} / \mathrm{L} \mathrm{Cd}^{2+}$ (Lechelt et al., 2000). The results of BEWs showed that the behavior strength of Japanese madaka could decrease to 0.2 in $10 \mathrm{~min}$ with $10 \mathrm{mg} / \mathrm{L}$ fenvalerate, and behavior strength of $D$. magna would decrease to zero within $3 \mathrm{hr}$ with $50.0 \mu \mathrm{g} / \mathrm{L}$ malathion (Ren et al., 2008, 2009a).

As the rapid development of the on-line biomonitoring of accidental pollution in recent decades, it is important to select suitable organisms to adapt the requirement of different purposes. So far, less research work has been carried out to assess the behavior characteristics of different aquatic organisms to the same stress. Therefore, in this study, the behavior rhythms, the sensitivity and the self-supportability were compared to evaluate the relative merits of D. magna and Japanese Madaka in the on-line biomonitoring of different purposes.

\section{Materials and methods}

\subsection{Equipment}

The movement behavior of test organisms was examined by BEWs conducted in Research Center for Eco-Environmental Science (Li et al., 2007). Test organisms were placed in a flow-through test chamber $(2 \mathrm{~cm}$ in length, $1.5 \mathrm{~cm}$ in diameter), which is closed off on both sides with nylon nets $(250 \mu \mathrm{m})$ (China Patent Number: ZL200710119338.9). One pair of electrodes at the walls of the test chambers sends a high frequency signal of altering current, which is received by a second pair of non current-carrying electrodes (Wang et al., 2007). The movement signal of test organisms is transformed by the $\mathrm{A} / \mathrm{D}$ transformer and the signal changes formed by the A/D transformer were analyzed automatically by software attached to the equipment. The monitoring data were analyzed using functions of "alarm generation", which is based on the alarm algorithm in an ARIMA-model (Ren et al., 2009b).

\subsection{Test species}

The experimental D. magna (48-hr young) were cultured in laboratory for more than 3 generations. The general culture of D. magna was maintained in the Standard Reference Water (ISO, 1996), at $(20 \pm 2)^{\circ} \mathrm{C}$ with $16 \mathrm{~L}$ : 8D photoperiod. D. magna were fed with a suspension of batch-cultured green algae (Scenedesmus obliquus).

Japanese madaka was collected from laboratory fish stock. The brood stock were kept in dechlorinated tap water at a constant temperature of $(20 \pm 2)^{\circ} \mathrm{C}$, with a photoperiod of $16 \mathrm{hr}: 8 \mathrm{hr}$ (light:dark). The brood stock was fed with newly hatched brine shrimp in the morning and flake food (Trea, Germany) in the afternoon. After 15 days, Japanese madaka was fed with flake food 2 times every day. Japanese madaka (2 months young) about 2.5$3.0 \mathrm{~cm}$ long was selected as the test organisms.

\subsection{Test chemicals}

Dichlorovos, deltamethrin and cadmium chloride were purchased from J\&K Chemical Ltd., China. All compounds were technical grade ( $>95 \%$ purity). Stock solutions (stored at $4^{\circ} \mathrm{C}$ until use) with proper concentration of each chemical were prepared in dimethyl sulfoxide (DMSO). All solvents were of analytical grade.

The concentration of DMSO in water was less than $0.5 \%$ in all experiments. A study has shown that DMSO of such concentration would neither lead to acute toxicity to $D$. magna nor affect the mobility of D. magna (Sandbacka et al., 2000).

\subsection{Experimental setup}

The on-line monitoring of the behavioral responses of D. magna and Japanese madaka were carried out under flow-through conditions to ensure that the dissolved oxygen in aquatic environment would not affect the normal behavior of test organisms. The differences of the behavior rhythms, the self-supportability and the sensitivity between D. magna and Japanese madaka were also investigated.

In these experiments, five healthy $D$. magna neonates (48-hr young) or 3 healthy madaka ( 2 months young) about $2.5-3.0 \mathrm{~cm}$ long were selected at random for each channel. Controlled flow rate of each test channel was about 2 liters per hour, which was proved to have no effect on the motility of test organisms (Guilhermino et al., 2000). The water temperature was maintained at $(20 \pm 2)^{\circ} \mathrm{C}$ with 16 hr:8 hr (light:dark) photoperiod. During these experiments, no food was added.

In these tests, the behavior strength that changed from 0 (lose the ability of movement) to 1 (full behavior express) was introduced to illustrate the differences of these behavioral responses of different organisms. The behavior strength data were sampled automatically by BEWs every $10 \mathrm{~min}$ and 6 data records in one hour were used to calculate the behavior strength average value. The judgment standard that behavior strength changed obviously was that: the around difference of behavior strength average value changed no less than $20 \%$ (Ren et al., 2009b).

The experiments on the behavior rhythms and on the self-supportability of both animals were carried out in SRW, and the behavior strength of different frequency (from 0.5 to $5.0 \mathrm{~Hz}$ ) was analyzed. In order to increase the reliability of results, the study on the behavior rhythms lasted for 4 days with 4 parallels, while on the selfsupportability it was lasted for 30 days with 4 parallels.

A 48-hr exposure experiment to dichlorovos, deltamethrin and cadmium chloride, respectively, were adopted to investigate the sensitivity of different species. Toxic unit was used for comparison, i.e., the 48-hr median lethal concentration $\left(\mathrm{LC}_{50}\right)$ for the chemical and for the test organism was taken as one unit (1 TU). The 48-hr exposure tests under flow-through conditions were performed for 3 concentration gradients, i.e., 1, 5, and $10 \mathrm{TU}$, respectively to evaluate the difference of the sensitivity of the two test organisms with the control of SRW. The experiments were repeated three times for each 
48-hr exposure.

\subsection{Statistical analyses}

The average values of the three repetitions of 48-hr exposure experiments were presented. If the data of the sensitivity differences of $D$. magna and Japanese madaka were distributed normally, determined by a KolmogorovSmirnov test, a single factor one-way analysis of variance (ANOVA) of SPSS 10.0 software was performed. If data were nonnormal, differences among the groups were tested with Kruskal-Wallis.

\section{Results and discussion}

\subsection{Behavior rhythms}

Figure 1a shows the behavior rhythms of Japanese madaka in SRW. The results suggested that the behavior changed synchronously at all frequencies. The low behavior strength could be observed for the high frequency. It was noticed that the behavior strength varied in a $24-\mathrm{hr}$ photoperiod. In general, behavior strength decreased in the dark (A in Fig. 1a), and increased in light (B in Fig. 1a). Therefore, behavior responses of Japanese madaka showed evident rhythms. Such rhythms variations were constant for all frequencies and repeatable in all the 4 parallels.

Figure $1 \mathrm{~b}$ shows the behavior rhythms of $D$. magna in SRW. The results suggested that the behavior at all frequencies kept in a relative steady level, and changed synchronously in most of time. But sometimes, the change degree at low frequency $(0.5 \mathrm{~Hz})$ behavior was faint $(\mathrm{A}$ in Fig. 1b), and behavior strength at high frequency $(1.0 \mathrm{~Hz})$ behavior might be higher than that at lower frequency $(0.5$ $\mathrm{Hz}$ ) behavior (B in Fig. 1b). The behavior strength change, which reflected the behavior rhythms directly, showed not as strong as those of Japanese madaka.

The behavioral responses might vary with organisms and environmental conditions. Photoperiod might work on the nerve system of different organisms and cause evident 24-hr behavior rhythms, which was called "circadian rhythms". This kind of rhythms was caused by "biological clock" (Wang et al., 2006). Every living being had an inherent biological clock that controlling behavioral response. The clock worked all the time, even when there were no outside signs to mark the passing of time (Binkley et al., 1978). The behavioral responses shown in Fig. 1 suggested that both D. magna and Japanese madaka should have the biological clock, but the circadian rhythms was more clear in Japanese madaka than that in D. magna. In the light period, behavior strength at $0.5 \mathrm{~Hz}$ for Japanese madaka could reach about 0.9 , but in the dark period, it would reach only about 0.4 (A, C in Fig. 1), or even down to zero (D in Fig. 1a). Although the behavior movement of D. magna showed also the circadian rhythms, the difference between light and dark periods were less evident than that of Japanese madaka (Fig. 1b). The circadian rhythms should be considered in the on-line monitoring. A calibration must be made to offset the differences of the behavior rhythms in different organisms to ensure the monitoring results and to reduce the false warning.

\subsection{Sensitivity}

According to previous works, LC50-48 for D. magna were $0.20(0.14-0.27) \mu \mathrm{g} / \mathrm{L}$ for dichlorvos (Kikuchi et al., 2000), $0.45 \mu \mathrm{g} / \mathrm{L}$ for deltamethrin (Ren et al., 2009b), and $55 \mu \mathrm{g} / \mathrm{L}$ for cadmium chloride (Nebeker et al., 1986). The values of LC50-48 for Japanese madaka about 2.5-3.0 $\mathrm{cm}$ long were $1 \mathrm{mg} / \mathrm{L}$ for dichlorvos, and $1.8 \mathrm{mg} / \mathrm{L}$ for cadmium chloride (Canton and Slooff, 1982). As there was no explicit report about the LC50-48 of deltamethrin to Japanese madaka, based on the 48-hr exposure results of Tilapia nilotica $(2.41 \mathrm{~cm}$ ) (Golow and Godzi, 1994), 15 $\mu \mathrm{g} / \mathrm{L}$ deltamethrin was regarded as $1 \mathrm{TU}$ in the sensitivity experiments. With the control of SRW, the behavioral

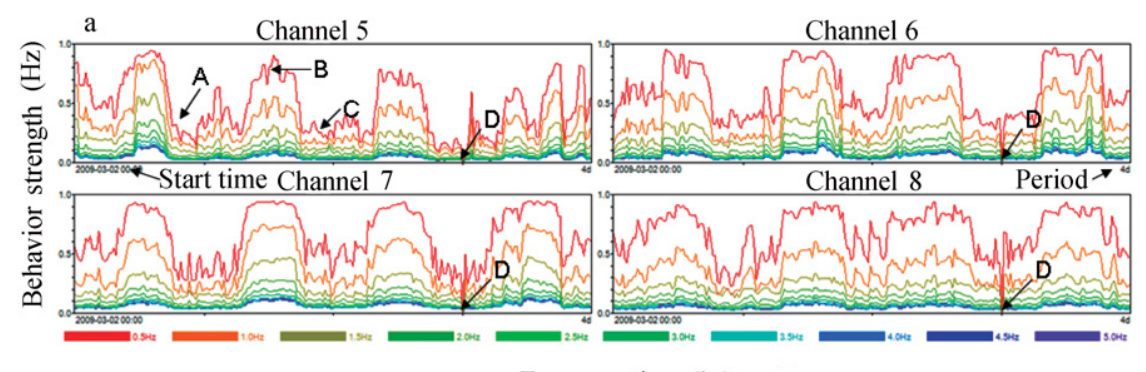

Exposure time (hr)

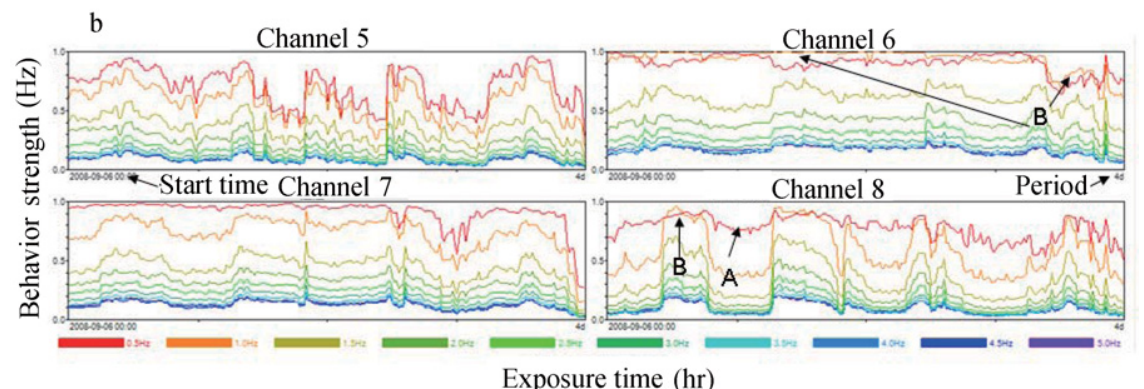

Fig. 1 Behavior rhythms of Japanese madaka (a) and D. magna (b) in SRW. Different curves showed in figure stand for different frequency behavior changed from 0.5 to $5.0 \mathrm{~Hz}$. 
responses of D. magna and Japanese madaka under different exposure concentrations were investigated to discuss the relative sensitivity.

Figure 2A shows the effects of dichlorvos, deltamethrin, and cadmium chloride on the behavioral responses of D. magna in 48-hr exposure. There was no significant change in behavioral responses in the control group. In the case of dichlorvos exposure, behavior strength of $D$. magna changed with exposure time and concentrations. Higher concentrations ( 5 and 10 TU) resulted in a greater decrease in the behavior strength, and a shorter response time during the first phase behavioral response, which was regarded as avoidance behavior (Sager et al., 2000; Erik et al., 2005; Ren et al., 2009a). The behavioral responses of D. magna to the exposures of deltamethrin, cadmium chloride and dichlorvos were similar (Fig. 2B) and they also changed with exposure time and concentration levels. If the exposure time was longer, the behavior strength of $D$. magna and Japanese madaka would decrease, especially at 5 and 10 TU. The decrease degree of behavior strength was different in different concentration levels: higher concentration (5 and $10 \mathrm{TU}$ ) would result in a greater decrease of behavior strength in a shorter time, and the ability of the duration of avoidance response was mainly affected by concentration levels (Ren et al., 2009b).

The results suggested that the behavioral responses of $D$. magna and Japanese madaka under different environment stresses were in accordance with the step-wise response model which was summarized in authors' previous report (Ren et al., 2009b). Namely, the movement behavior in almost all the exposures decreased step by step until intoxication, some exposure caused a gradually decreased movement behavior followed by a regulatory response or followed different adjustment/readjustment patterns. The duration of avoidance response, which was defined as time between beginning of the exposure and a significant decrease $(20 \%)$ in behavior strength, varied with the concentrations of dichlorvos, deltamethrin, and cadmium chloride. Therefore, based on the step-wise response model, the behavioral responses of D. magna and Japanese madaka under different exposure scenarios could satisfy the pre-conditions of the early warning of an accidental pollution in aquatic environment.

Although the behavioral responses of D. magna and Japanese madaka under different exposures were regular and could be described with the step-wise response model, their sensitivities were different. As shown in Table 1, the sensitivities of $D$. magna and Japanese madaka were compared with the Water Quality Standards (GB38382002). This could be helpful in the selection of the test

Table 1 Sensitivity of D. magna and Japanese madaka comparing with the Water Quality Standards

\begin{tabular}{llll}
\hline Chemical & $\begin{array}{l}\text { Water quality } \\
\text { standards } \\
(\mathrm{GB} 3838-2002)\end{array}$ & $\begin{array}{l}\text { Detection } \\
\text { limit of } \\
\text { D. magna }\end{array}$ & $\begin{array}{l}\text { Detection } \\
\text { limit of } \\
\text { Japanese } \\
\text { madaka }\end{array}$ \\
\hline Dichlorvos $(\mu \mathrm{g} / \mathrm{L})$ & 50 & 0.20 & 1000 \\
Deltamethrin $(\mu \mathrm{g} / \mathrm{L})$ & 20 & 0.45 & $\begin{array}{l}15 \\
\text { Cadmium chloride }(\mu \mathrm{g} / \mathrm{L})\end{array}$ \\
$17\left({\left.\text { in } \mathrm{CdCl}_{2}\right)}\right)$ & 55 & 1800 \\
\hline
\end{tabular}

A

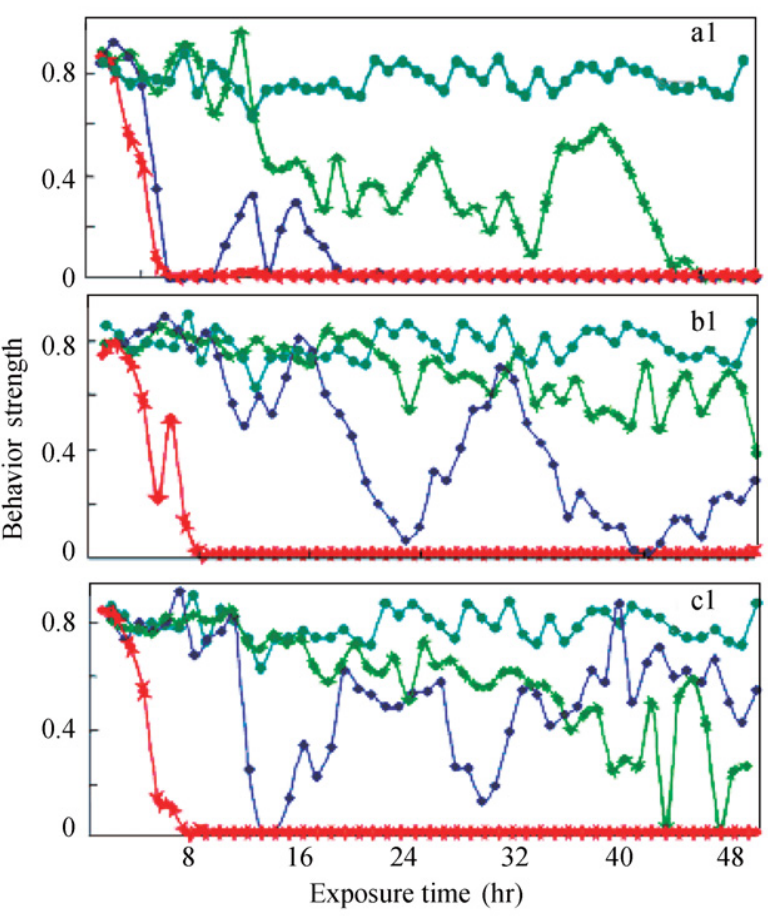

B
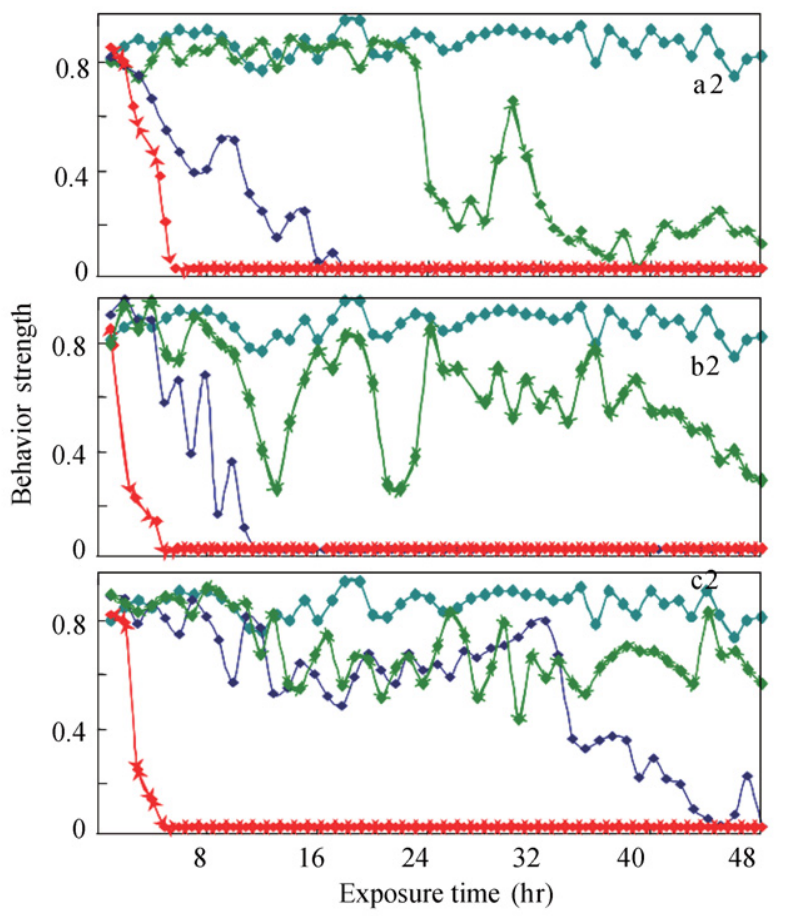

Fig. 2 Effects of dichlorvos (a1, a2), deltamethrin (b1, b2), and cadmium chloride (c1, c2) on the behavioral responses of D. magna (A) and Japanese madaka (B) in 48-hr exposure. 


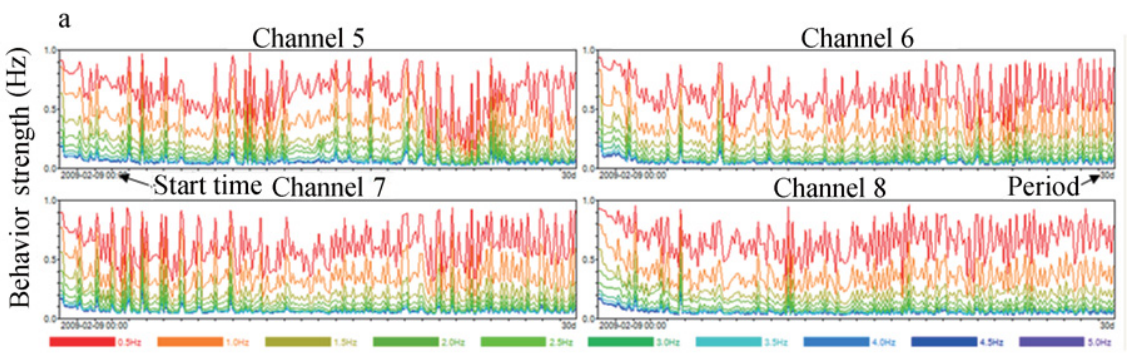

Exposure time (hr)

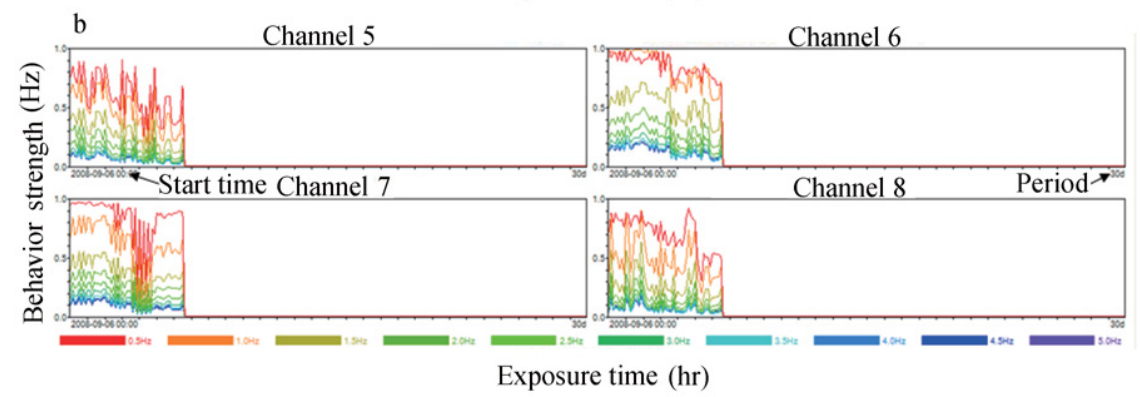

Fig. 3 Behavioral responses of Japanese madaka (a) and D. magna (b) in SRW with a 30-day period.

organism for certain application purpose. For the tested chemicals, D. magna was more sensitive, and it could be used as bioindicators to a concentration closing to the water quality standards.

\subsection{Self-supportability}

As no food would be added in the on-line biomonitoring of aquatic environment, the self-supportability was very important for the test organisms.

In the self-supportability test, Japanese madaka in SRW in a 30-day period (Fig. 3a) could live without feeding till the end of the experiment. In the 30-day period, the behavior movement maintained the similar behavior rhythms, and showed clear circadian rhythms. This property was useful when long term biomonitoring was required in insitu conditions, where periodical feeding could increase the labor of maintenance and costs.

Figure $3 \mathrm{~b}$ shows the behavioral responses of $D$. magna in SRW with a 30-day period. The results suggested that $D$. magna could only live about 7 days and behavior strength decreased obviously from day 5. Without feeding, the normal behavioral responses of $D$. magna could only last for about 4 days.

From the differences of the self-supportability between D. magna and Japanese madaka, it could be seen that Japanese madaka was more stronger than D. magna and was suitable for long-term biomonitoring of the accidental pollution in aquatic environment.

\section{Conclusions}

The movement characteristics of both aquatic organisms showed the circadian rhythms and the 24-hr behavior rhythms caused by an inner biological clock affected the behavioral responses evidently. Therefore, a calibration should be made before behavior response was used for biomonitoring.

Based on the results of the sensitivity, the minimum detect concentrations of D. magna were close to the Water Quality Standards, however, except deltamethrin, the minimum detect concentrations of Japanese madaka were 20 and 100 times higher than the Water Quality Standards respectively in dichlorvos and cadmium chloride. Combining the sensitivity and the self-supportability of two species, we concluded that the selection of test animal in a biomonitor depended on the purposes. Japanese madaka should be better for applications where long term, in-situ monitoring of accidental discharge is required; while D. magna should be used in circumstances where sensitive detection of toxic contamination in water with the replacement of test animals less than 4 days.

\section{Acknowledgments}

This work was supported by the National Key Program for Water Pollution Control (No. 2009ZX07210-009, 2009ZX07209-005, 2009ZX07527-002) and the State Key Laboratory of Environmental Aquatic Chemistry (No. 08K07ESPCR).

\section{References}

Andrew S K, James D S, Geoffrey T G, Timothy C A M, Colin H, 2004. A video-based movement analysis system to quantify behavioral stress responses of fish. Water Research, 38: 3993-4001.

Binkley S A, Riebman J B, Reilly K B, 1978. The pineal gland: A biological clock in vitro. Science, 202: 1198-1120.

Canton J H, Slooff W, 1982. Toxicity and accumulation studies of cadmium $\left(\mathrm{Cd}^{2+}\right)$ with freshwater organisms of sifferent trophic levels. Ecotoxicology and Environment Safety, 6(1): 113-128

Chai C G, Li M, Wang Y H, 2004. Problems and suggestions of water quality monitoring for accidental water pollution events. China Water Resources, 15: 52-53.

Chon C, Kwak I, Kim J, Koh S, Lee S, Leem J, 2005. Movement behavior of madaka (Oryzias latipes) in response to sublethal treatment of diazinon and cholinesterase activity 
in semi-natural conditions. Environmental Monitoring and Assessment, 101: 1-21.

Erik H, Finn-Arne W, Joachim S, Svante W, Holger U, 2005. Avoidance behavior and brain monoamines in fish. Brain Research, 1032: 104-110.

Gerhardt A, Schmidt S, Höss S, 2002. Measurement of movement patterns of Caenorhabditis elegans (Nematoda) with the Multispecies Freshwater Biomonitor - a potential new method to study a behavioural toxicity parameter of nematodes in sediment. Environmental Pollution, 120(3): 19-22.

Golow A A, Godzi T A, 1994. Acute toxicity of deltamethrin and dieldrin to rreochromis niloticus (LIN). Bulletin of Environmental Contamination and Toxicology, 52(3): 351354.

Gormley K L, Teather K L, 2003. Developmental, behavioral, and reproductive effects experienced by Japanese madaka (Oryzias latipes) in response to short-term exposure to endosulfan. Ecotoxicology and Environmental Safety, 54: 330-338.

Gray M A, Teather K L, Metcalfe C D, 1999. Reproductive success and behavior of Japanese madaka (Oryzias latipes) exposed to 4-tert-octylphenol. Environmental Toxicology and Chemistry, 18: 2587-2594.

Green U, Kremer J H, Zillmer M, Moldaenke C, 2003. Detection of chemical threat agents in drinking water by an early warning real-time biomonitor. Environmental Toxicology, 18(6): 368-374.

Guilhermino L, Diamantino T, Silva M C, Soares A M V M, 2000. Acute toxicity test with Daphnia magna: An alternative to mammals in the prescreening of chemical toxicity. Ecotoxicology and Environmental Safety, 46: 357362.

Heckmann L H, Callaghan A, Hooper H L, Connon R, Hutchinson T H, Maund S J et al., 2007. Chronic toxicity of ibuprofen to Daphnia magna: Effects on life history traits and population dynamics. Toxicology Letter, 172: 137-145.

ISO (International Organization for Standardization), 1996. Water quality-determination of the acute lethal toxicity of substances to a freshwater fish [Brachdanio rerio (Hamilton-Buchanan), Teleostei, Cyprinidae] -Part 3: Flowthrough method. ISO/ DIS 7346/3.

Kikuchi M, Sasaki Y, Wakabayashi M, 2000. Screening of organophosphate insecticide pollution in water using Daphnia magna. Ecotoxicology and Environmental Safety, 47: 239-245.

Lechelt M, Blohm W, Kirschneit B, Pfeiffer M, Gresens E, Liley $\mathrm{J}$ et al., 2000. Monitoring of surface water by ultra-sensitive Daphnia-Toximeter. Environmental Toxicology, 15: 390400.

Li Z L, Ren Z M, Ma M, Zha J M, Wang Z J, Fu R S, 2007. Research on the behavioral responses of Daphnia magna in the early warning of organophosphorous pesticide contamination. China Water and Wastewater. 23(12): 7375.

Martínez-Jerónimo F, Villaseor R, Ríos G, Espinosa-Chavez F, 2005. Toxicity of the crude oil water-soluble fraction and kaolin-adsorbed crude oil on Daphnia magna (Crustacea: Anomopoda). Archives of Environmental Contamination and Toxicology, 48: 444-449.

Nebeker A V, Cairns M A, Onjukka S T, Titus R H, 1986. Effect of age on sensitivity of Caphnia magna to cadmium, copper and cyanazine. Environmental Toxicology and Chemistry, 5(6): 527-530.
OECD (Organization for Economic Co-operation and Development), 1999. Final Report of the Fish Expert Consultation Meeting, London, UK, October, 28-29, 1998.

Oshima Y, Kang I, Kobayashi M, Nakayama K, Imada N, Honjo $\mathrm{T}$, 2003. Suppression of sexual behavior in male Japanese madaka (Oryzias latipes) exposed to $17 \beta$-estradiol. Chemosphere, 50: 429-436.

Putman R J, Wratten S D, 1984. Principles of Ecology. Groom Helm, London and Canberra.

Ren Z M, Li Z L, Rao K F, Wang Z J, Zhao L T, Wang P et al., 2008. The differences of the behavioral responses of Japanese Medaka (Oryzias latipes) in the exposure of fenvalerate and cadmium chloride. Asian Journal of Toxicology, 3: 563-569.

Ren Z M, Li Z L, Zha J M, Ma M, Wang Z J, Gerhardt A, 2007. The early warning of aquatic organophosphorus pesticide contamination by on-line monitoring behavioral changes of Daphnia magna. Environment Monitoring and Assessment, 134: 373-383.

Ren Z M, Li Z L, Zha J M, Rao K F, Ma M, Wang Z J, 2009a. The avoidance responses of Daphnia magna to the exposure of organophosphorus pesticides in an on-line biomonitoring system. Environment Modeling and Assessment, 14: 405410.

Ren Z M, Li Z L, Zha J M, Ma M, Wang Z J, Fu R S, 2009b. Behavioral responses of Daphnia magna to stresses of contaminants with different toxic mechanisms. Bulletin of Environmental Contamination and Toxicology, 82: 310 316.

Rodriguez M, Sanders C A, Greenbaum E, 2002. Biosensors for rapid monitoring of primary-source drinking water using naturally occurring photosynthesis. Biosensors and Bioelectronics, 17: 843-849.

Rosa E, Barata C, Damasio J, Bosch M P, Guerrero A, 2006. Aquatic ecotoxicity of a pheromonal antagonist in Daphnia magna and Desmodesmus subspicatus. Aquatic Toxicology, 79: 296-303.

Sager D R, Hocutt C H, StaufferJr J R, 2000. Avoidance behavior of Morone americana, Leiostomus xanthurus and Brevoortia tyrannus to strobe light as a method of impingement mitigation. Environmental Science Policy, 3: 393-403.

Sandbacka M, Christianson I, Isomaa B, 2000. The acute toxicity of surfactants on fish cells, Daphnia magna and fish - A comparative study. Toxicology in Vitro, 14: 61-68.

Sturm A, Hansen P D, 1999. Altered cholinesterase and monooxygenase levels in Daphnia magna and Chironomus riparius exposed to environmental pollutants. Ecotoxicology and Environment Safety, 42: 9-15.

Tomasik P, Warren D M, 1996. The use of Daphnia in studies of metal pollution of aquatic systems. Environment Research, 4: 25-64.

Wang G D, Fu C L, Li J X, Du Y Z, Tong J, 2006. Circadian rhythms and different photoresponses of Clock gene transcription in the rat suprachiasmatic nucleus and pineal gland. Acta Physiologica Sinica, 58: 359-364.

Wang Y J, Liu X B, Hu J H, Li L, Li Y W, 2007. The simulation and experimental study of conductance sensor's electric field distribution. Petroleum Instruments, 1(21): 16-18.

Yang W, Nan J, Sun D Z, 2008. An online water quality monitoring and management system developed for the Liming River basin in Daqing, China. Journal of Environmental Management, 88(2): 318-325. 